\title{
Naturopathic medicine for the prevention of cardiovascular disease: a randomized clinical trial
}

\author{
Dugald Seely ND MSc, Orest Szczurko ND MSc, Kieran Cooley ND, Heidi Fritz ND MA, Serenity Aberdour ND, \\ Craig Herrington ND, Patricia Herman ND PhD, Philip Rouchotas MSc ND, David Lescheid ND PhD, \\ Ryan Bradley ND MPH, Tara Gignac ND, Bob Bernhardt LLM PhD, Qi Zhou PhD, Gordon Guyatt MD MSc
}

See related editorial at www.cmaj.ca/lookup/doi/10.1503/cmaj.130614

\begin{abstract}
Background: Although cardiovascular disease may be partially preventable through dietary and lifestyle-based interventions, few individuals at risk receive intensive dietary and lifestyle counselling. We performed a randomized controlled trial to evaluate the effectiveness of naturopathic care in reducing the risk of cardiovascular disease.
\end{abstract}

Methods: We performed a multisite randomized controlled trial of enhanced usual care (usual care plus biometric measurement; control) compared with enhanced usual care plus naturopathic care (hereafter called naturopathic care). Postal workers aged 25-65 years in Toronto, Vancouver and Edmonton, Canada, with an increased risk of cardiovascular disease were invited to participate. Participants in both groups received care by their family physicians. Those in the naturopathic group also received individualized care (health promotion counselling, nutritional medicine or dietary supplementation) at 7 preset times in work-site clinics by licensed naturopathic doctors. The body weight, waist circumference, lipid profile, fasting glucose levels and blood pressure of participants in both groups were measured 3 times during a 1-year period. Our primary outcomes were the 10-year risk of having a cardiovascular event (based on the Framingham risk algorithm) and the prevalence of metabolic syndrome (based on the Adult Treatment Panel III diagnostic criteria).

Results: Of 246 participants randomly assigned to a study group, 207 completed the study. The characteristics of participants in both groups were similar at baseline. Compared with participants in the control group, at 52 weeks those in the naturopathic group had a reduced adjusted 10-year cardiovascular risk (control: 10.81\%; naturopathic group: 7.74\%; risk reduction $-3.07 \%$ [95\% confidence interval (CI) $-4.35 \%$ to $-1.78 \%$ ], $p<0.001$ ) and a lower adjusted frequency of metabolic syndrome (control group: $48.48 \%$; naturopathic care: $31.58 \%$; risk reduction $-16.90 \%[95 \% \mathrm{Cl}$ $-29.55 \%$ to $-4.25 \%$ ], $p=0.002$ ).

Interpretation: Our findings support the hypothesis that the addition of naturopathic care to enhanced usual care may reduce the risk of cardiovascular disease among those at high risk. Trial registration: ClinicalTrials.gov, no. NCT0071879.
Competing interests: See end of article.

This article has been peer reviewed.

Correspondence to:

Dugald Seely,

dseely@ccnm.edu

CMAJ 2013. DOI:10.1503 /cmaj.120567

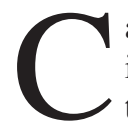
ardiovascular disease is the second leading cause of death in Canada. ${ }^{1}$ Observational studies, including a large international case-control study, have shown that several modifiable behavioural factors contribute to the risk of cardiovascular disease. ${ }^{2}$ Metabolic syndrome, a cluster of modifiable risk factors for atherosclerotic cardiovascular disease, is strongly associated with increased risk of cardiovascular-related mortality. ${ }^{3,4}$ Guidelines by the American Heart Association and the United States Preventive Services Task Force recommend lifestyle interventions as an important part of cardiovascular disease prevention. ${ }^{5,6}$ Although the importance of lifestyle intervention is widely recognized, few individuals with, or at risk of, cardiovascular disease receive intensive dietary and lifestyle counselling. ${ }^{7.8}$

A variety of health care practitioners routinely deliver diet and health promotion advice to patients at risk of cardiovascular disease. Naturopathic doctors in North America are trained and regulated practitioners who emphasize this form of self-directed care. Several retrospective analyses have suggested that patients at risk of cardiovascular disease receive lifestyle counselling routinely as part of naturopathic care. ${ }^{9-11}$ However, no rigorous studies have examined the effectiveness 
of these approaches. To evaluate the effectiveness of representative naturopathic approaches to reducing the risk of cardiovascular disease, we conducted a randomized clinical trial of a multimodality nutritional and physical activity intervention in a workplace setting.

\section{Methods}

\section{Study design}

This study was a 2-arm, parallel, randomized clinical trial conducted at multiple work sites from 2008 to 2010. Unrestricted free screening for all Canada Post employees was conducted in Toronto, Vancouver and Edmonton, Canada. All workers were encouraged to undergo screening, and consenting individuals had their blood pressure and lipid and glucose levels assessed. Nonfasting blood samples obtained by finger prick were analyzed for glucose, total cholesterol, lowdensity lipoprotein (LDL), high-density lipoprotein (HDL), triglycerides and the ratio of total cholesterol to HDL using the Cholestech LDX System (Inverness Medical) point-of-care device. Resting blood pressure was measured using the automated BPM-100 mobile sphygmomanometer (BPTru).

Randomization was conducted centrally at the Canadian College of Naturopathic Medicine in blocks of 8 stratified by sex. Participants were asked to fast for 12 hours before the baseline visit. Participants, clinicians and those collecting outcome data or adjudicating outcomes were aware of group assignment. The statisticians were unaware of group allocation.

\section{Participant selection}

We included members of the Canadian Union of Postal Workers who were aged 25-65 years, under the care of a primary care physician, able to answer self- and interviewer-administered questions in English, and able to provide written informed consent. We excluded women who were pregnant or breastfeeding or who intended to become pregnant in following year. We also excluded people with a history of myocardial infarction within the past 6 months or who had chronic kidney or liver disease. We excluded people with lower relative ratios of total cholesterol to HDL $(<1.8)$.

At each site, we invited 120-140 participants with the highest risk of cardiovascular disease (based on the ratio of total cholesterol to HDL; mean: 5.18; range: $1.8-14.8$ ).

\section{Interventions}

In both enhanced usual care (control) and naturopathic care plus enhanced usual care (hereafter called naturopathic care) groups, licensed naturopathic doctors measured body weight, waist circumference, lipid profile, fasting glucose and blood pressure 3 times during the study (baseline, $26 \mathrm{wk}, 52 \mathrm{wk})$. Because our objective was to assess the effect of adding naturopathic care to usual care, participants were advised to continue seeing their family physician for routine care, without recommending changes in the frequency of visits.

Participants in the naturopathic group received naturopathic care at 7 preset times over a 1-year period, at a frequency that was somewhat typical of routine naturopathic care in the community. The initial visit was 1 hour, with subsequent 30-minute follow-up visits. For consistency with naturopathic practice, treatment recommendations were individualized from a predetermined menu of interventions based on which risk factors were present and patient preferences (Appendix 1, available at www.cmaj.ca /lookup/suppl/doi:10.1503/cmaj.120567/-/DC1). Therapies included specific diet and lifestyle recommendations and the prescription of selected natural health products. Because a range of interventions were recommended to participants in the naturopathic group, the frequency and composition of each recommendation as well as participant adherence are not reported. We did not have direct control over the care given to the control group; thus, we did not track or report recommendations made by the participants' family physicians.

The menu of therapies was guided by an expert advisory process, during which 4 naturopathic doctors (P.R., R.B., D.L., T.G.) provided guidance to trial clinicians based on existing peer-reviewed published evidence and clinical experience. This process resulted in a trial manual of therapies provided to each of the 3 clinicians (O.S., S.A., C.H.) to guide their practice. The recommended interventions included weight loss of about 2.3-4.6 kg through a combination of caloric restriction and regular physical activity. ${ }^{5,12}$ Dietary recommendations were based on components of the Mediterranean and Portfolio dietary regimes. ${ }^{13,14}$ Examples of prescriptions for natural health products included omega-3 fatty acids eicosapentaenoic acid and docosahexaenoic acid, ${ }^{12,15}$ soluble fibre, ${ }^{16}$ coenzyme Q10 ${ }^{17}$ and plant sterols $^{5}$ (Appendix 1).

\section{Outcomes}

Our a priori defined primary outcomes included changes in the prevalence of metabolic syndrome and changes in Framingham 10-year cardiovascular risk score. The Adult Treatment Panel III defines metabolic syndrome as the presence of 
3 of 5 risk factors: abdominal obesity (defined as a waist circumference of $\geq 102 \mathrm{~cm}$ for men and $\geq 88 \mathrm{~cm}$ for women); triglycerides $\geq 1.70 \mathrm{mmol} / \mathrm{L}$ or taking medication for elevated triglyceride; HDL cholesterol $<1.03 \mathrm{mmol} / \mathrm{L}$ for men or $<1.3$ $\mathrm{mmol} / \mathrm{L}$ for women; systolic blood pressure $\geq 130 \mathrm{~mm} \mathrm{Hg}$ or diastolic blood pressure $\geq 85 \mathrm{~mm}$ $\mathrm{Hg}$ or taking antihypertensive medication; or fasting blood glucose $\geq 5.6 \mathrm{mmol} / \mathrm{L}$ or taking medication for diabetes. ${ }^{5}$

The Framingham algorithm is a tool designed to estimate an individual's level of cardiovascular disease risk. The algorithm predicts the 10year risk of a cardiovascular event based on a composite score of risk factors, including age, HDL, total cholesterol, systolic blood pressure, smoking status and diabetes status. ${ }^{18}$

Our secondary outcomes included changes in individual risk factors, changes in quality of life (measured by use of the Short Form Health Survey $^{19}$ and the Measure Yourself Medical Outcomes Profile questionnaire ${ }^{20-22}$ ) and adverse events.

The naturopathic doctors collected all biometric and validated questionnaire measures at baseline, 26 weeks and 52 weeks for both groups. Figure 1 shows the flow of patients through the trial. Safety was monitored at each visit by use of a checklist and an open-ended question. Clinicians recorded participant-reported adverse events and graded them according to Health Canada's regulations under the Food and Drug Act.

\section{Statistical analysis}

We summarized the data using means with standard deviations or counts with proportions. To evaluate the group differences over time, we used the repeated measures of the mixed-model for continuous outcomes or the generalized estimating equations model for binary data. We included the baseline measures of the outcome variables as covariables in the models. We reported the baseline adjusted estimate of the group difference with the $95 \%$ confidence interval (CIs) at weeks 26 and 52.

For the primary outcomes of metabolic syndrome and cardiovascular risk, we used a multiple imputation method for missing data. The variables used in this procedure were age, sex, exercise level, body mass index (BMI), waist to hip ratio, smoking status, HDL and ratio of total cholesterol to HDL.

\section{Ethics approval}

The trial was approved by the Research Ethics Board of the Canadian College of Naturopathic Medicine and was registered at www.clinicaltrials .gov (NCT00718796).

\section{Results}

We selected 246 people for inclusion and randomization; 124 were randomly assigned to the naturopathic group and 122 were assigned to the

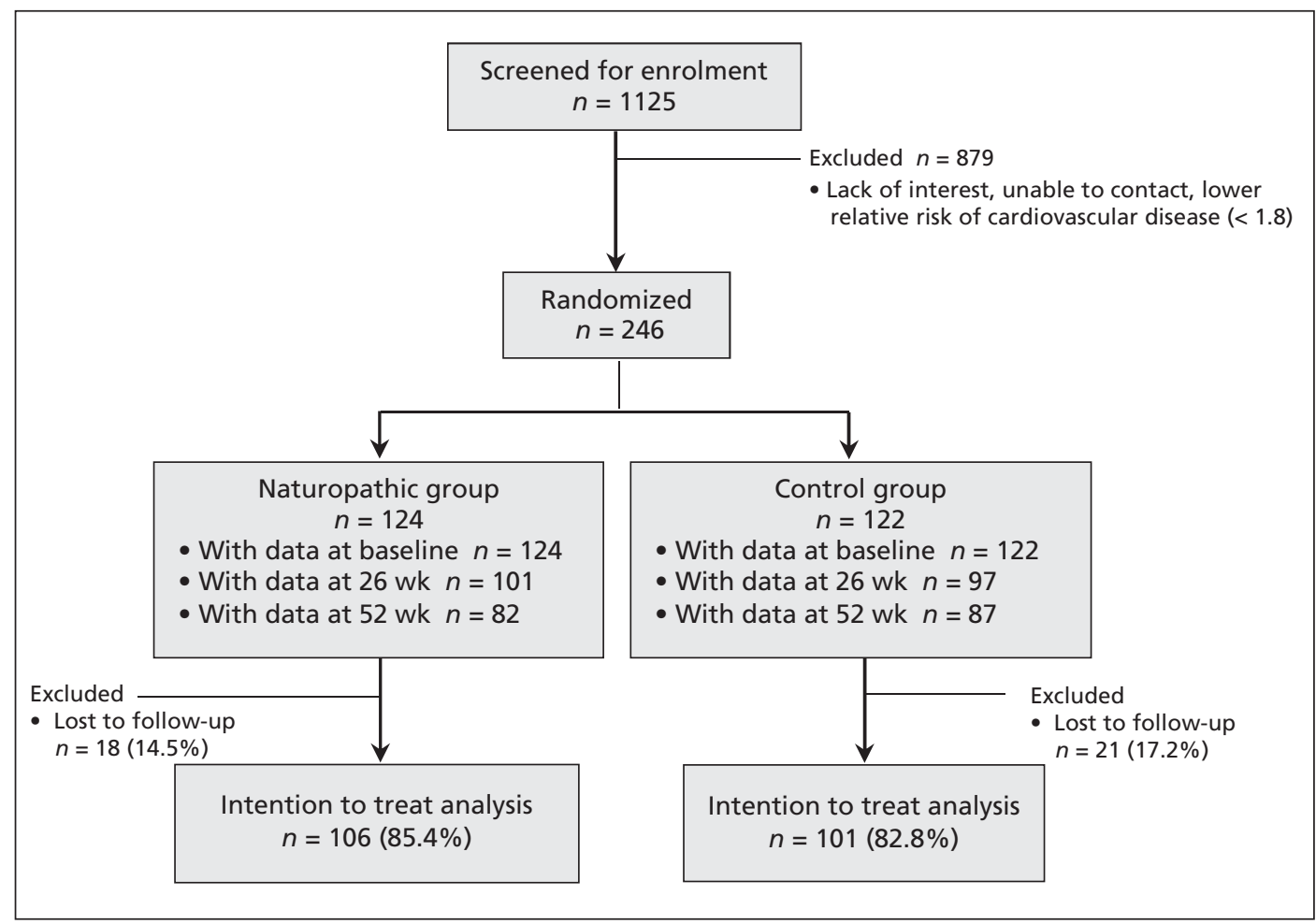

Figure 1: Flow of participants through the study. Participants in the control group received enhanced usual care, and participants in the naturopathic group received naturopathic care plus enhanced usual care. 
control group. The groups were similar at baseline (Table 1), although the naturopathic group had a nonsignificantly higher prevalence of metabolic syndrome, larger waist and hip circumference, and greater weight. The naturopathic group reported significantly more weekly minutes of moderate exercise.

\section{Primary outcomes}

After 1 year, the naturopathic group had better outcomes than the control group. After adjustment for baseline differences, the proportion with metabolic syndrome in the control group was $48.48 \%$ and the proportion in the naturopathic group was $31.58 \%$, reflecting a risk reduction of
$-16.90 \%(95 \% \mathrm{CI}-29.55 \%$ to $-4.25 \%) ; p=$ 0.002 . For cardiovascular risk, the proportions were $10.81 \%$ in the control group and $7.74 \%$ in the naturopathic group, a risk reduction of $-3.07 \%$ (95\% CI -4.35 to $-1.78 \%$; $p<0.001$; Table 2).

Although the treatment group improved more than the control group for almost all secondary outcomes, most were not statistically significant (Table 2 and Appendix 2, available at www.cmaj.ca /lookup/suppl/doi:10.1503/cmaj.120567/-/DC1). Notable significant results were reductions in waist circumference, ratio of total cholesterol to HDL, and scores for symptoms 1 and 2 (self-identified as important symptoms of concern) on the Measure Table 1: Baseline characteristics of participants at high risk of cardiovascular disease who received enhanced usual care (control) or
naturopathic care

\begin{tabular}{|c|c|c|c|c|}
\hline \multirow[b]{2}{*}{ Characteristics } & \multicolumn{2}{|c|}{ Naturopathic care, $n=124$} & \multicolumn{2}{|c|}{ Control, $n=122$} \\
\hline & $n$ & Mean \pm SD or no. $(\%)^{*}$ & $n$ & Mean \pm SD or no. $(\%)^{*}$ \\
\hline Metabolic syndromet & 107 & $59(55.1)$ & 113 & $49(43.4)$ \\
\hline Cardiovascular risk $\dagger$ & 109 & $10.73(8.13)$ & 114 & $9.54(6.88)$ \\
\hline Height, m & 109 & $1.69 \pm 0.1$ & 114 & $1.7 \pm 0.1$ \\
\hline Weight, kg & 109 & $85.5 \pm 20.9$ & 114 & $81.8 \pm 16.7$ \\
\hline Body mass index & 109 & $29.5 \pm 7.0$ & 112 & $28.3 \pm 5.3$ \\
\hline Waist circumference, $\mathrm{cm}$ & 109 & $101.8 \pm 13.6$ & 112 & $98.9 \pm 12.9$ \\
\hline Hip circumference, cm & 109 & $109.3 \pm 13.6$ & 112 & $106.5 \pm 9.6$ \\
\hline Waist to hip ratio & 109 & $0.93 \pm 0.06$ & 112 & $0.93 \pm 0.06$ \\
\hline $\mathrm{LDL}, \mathrm{mmol} / \mathrm{L}$ & 98 & $3.49 \pm 0.98$ & 108 & $3.3 \pm 0.98$ \\
\hline $\mathrm{HDL}, \mathrm{mmol} / \mathrm{L}$ & 108 & $1.15 \pm 0.48$ & 112 & $2.09 \pm 10.29$ \\
\hline Triglycerides, mmol/L & 110 & $2.29 \pm 1.34$ & 114 & $2.25 \pm 1.26$ \\
\hline Ratio of total cholesterol to HDL & 105 & $5.27 \pm 1.57$ & 112 & $5 \pm 1.17$ \\
\hline Glycated hemoglobin, \% & 109 & $5.81 \pm 1.06$ & 113 & $5.7 \pm 0.97$ \\
\hline Fasting blood glucose, $\mathrm{mmol} / \mathrm{L}$ & 110 & $5.86 \pm 1.91$ & 114 & $5.72 \pm 1.77$ \\
\hline Systolic blood pressure, $\mathrm{mm} \mathrm{Hg}$ & 109 & $125.5 \pm 16.4$ & 114 & $123.2 \pm 17.0$ \\
\hline Diastolic blood pressure, $\mathrm{mm} \mathrm{Hg}$ & 109 & $81.9 \pm 10.9$ & 114 & $81.9 \pm 10.9$ \\
\hline Current smoker & 109 & $9(11.3)$ & 113 & $18(15.8)$ \\
\hline No. of packs per week, if smoked, median (IQR) & 9 & $5(3.5-7)$ & 18 & $3.68(2-7)$ \\
\hline Alcohol use & 109 & $48(44.0)$ & 114 & $50(43.9)$ \\
\hline No. of drinks per week, if consumed alcohol & 48 & $6.67 \pm 7$ & 50 & $6.44 \pm 8.45$ \\
\hline Caffeine use & 109 & $93(85.3)$ & 113 & $105(92.9)$ \\
\hline Cups/wk, all participants & 109 & $14.96 \pm 14.9$ & 113 & $12.92 \pm 12.13$ \\
\hline Cups/wk, if consumed caffeine & 93 & $17.54 \pm 14.67$ & 105 & $13.90 \pm 12.02$ \\
\hline \multicolumn{5}{|l|}{ Exercise intensity, $\mathrm{min} / \mathrm{wk}$} \\
\hline Low & 107 & $146.7 \pm 374.3$ & 114 & $153.2 \pm 399.2$ \\
\hline Medium & 109 & $15.9 \pm 44.9$ & 112 & $3.7 \pm 18.2$ \\
\hline High & 109 & $8.4 \pm 50.9$ & 112 & $3.5 \pm 22.1$ \\
\hline
\end{tabular}


Yourself Medical Outcomes Profile questionnaire, general wellbeing and reduction in medication (number of medications and/or dosage).

\section{Safety and adverse events}

Serious adverse events were similar in both groups. In the naturopathic group, 1 participant died before starting treatment, and 1 patient had acute diverticulitis that required admission to hospital. In the control group, cancer was diagnosed in 2 participants, 1 participant experienced a myocardial infarction, and 1 participant

Table 2: Primary and secondary outcomes after 26 and 52 weeks*

\begin{tabular}{|c|c|c|c|}
\hline Outcomes & $\begin{array}{l}\text { Naturopathic care } \\
\text { Mean or } \% \pm \mathrm{SE} \\
\quad n=124\end{array}$ & $\begin{array}{l}\text { Control } \\
\text { Mean or } \% \pm \mathrm{SE} \\
n=122\end{array}$ & $\begin{array}{l}\text { Estimated difference } \\
\text { (control - naturopathic care) } \\
\qquad(95 \% \mathrm{Cl})\end{array}$ \\
\hline \multicolumn{4}{|c|}{ Primary outcomes } \\
\hline \multicolumn{4}{|c|}{ Metabolic syndrome, $† \%$} \\
\hline $26 w k$ & $38.11 \pm 0.04$ & $53.05 \pm 0.04$ & $-14.94 \%(-26.49 \%$ to $-3.39 \%)$ \\
\hline $52 \mathrm{wk}$ & $31.58 \pm 0.04$ & $48.48 \pm 0.05$ & $-16.90 \%(-29.55 \%$ to $-4.25 \%)$ \\
\hline \multicolumn{4}{|c|}{ 10-year cardiovascular risk, $+\%$} \\
\hline 26 wk & $8.99 \pm 0.44$ & $11.35 \pm 0.47$ & $-2.36(-3.66$ to -1.09$)$ \\
\hline $52 \mathrm{wk}$ & $7.74 \pm 0.46$ & $10.81 \pm 0.47$ & $-3.07(-4.35$ to -1.78$)$ \\
\hline \multicolumn{4}{|c|}{ Secondary outcomes } \\
\hline \multicolumn{4}{|l|}{ Weight, kg } \\
\hline $26 w k$ & $82.44 \pm 0.68$ & $83.76 \pm 0.70$ & $-1.32(-3.25$ to 0.61$)$ \\
\hline $52 \mathrm{wk}$ & $83.81 \pm 1.07$ & $83.59 \pm 1.09$ & $0.22(-2.78$ to 3.22$)$ \\
\hline \multicolumn{4}{|c|}{ Low-density lipoprotein, mmol/L } \\
\hline $26 w k$ & $3.54 \pm 0.10$ & $3.71 \pm 0.10$ & $-0.17(-0.44$ to -0.11$)$ \\
\hline $52 w k$ & $3.49 \pm 0.10$ & $3.50 \pm 0.09$ & $-0.01(-0.28$ to 0.25$)$ \\
\hline \multicolumn{4}{|c|}{ High-density lipoprotein, mmol/L } \\
\hline $26 w k$ & $1.18 \pm 0.04$ & $1.13 \pm 0.04$ & $0.05(-0.06$ to 0.16$)$ \\
\hline $52 \mathrm{wk}$ & $1.18 \pm 0.04$ & $1.04 \pm 0.04$ & $0.14(0.04$ to 0.24$)$ \\
\hline \multicolumn{4}{|c|}{ Triglyceride, $\mathrm{mmol} / \mathrm{L}$} \\
\hline 26 wk & $2.69 \pm 0.37$ & $2.46 \pm 0.38$ & $0.23(-0.82$ to 1.27$)$ \\
\hline $52 \mathrm{wk}$ & $2.2 \pm 0.19$ & $2.23 \pm 0.19$ & $-0.03(-0.56$ to 0.5$)$ \\
\hline \multicolumn{4}{|c|}{ Ratio of total cholesterol to HDL } \\
\hline $26 w k$ & $5.12 \pm 0.14$ & $5.33 \pm 0.15$ & $-0.21(-0.61$ to 0.19$)$ \\
\hline $52 w k$ & $4.84 \pm 0.16$ & $5.63 \pm 0.16$ & $-0.79(-1.24$ to -0.35$)$ \\
\hline \multicolumn{4}{|c|}{ Glycated hemoglobin, \% } \\
\hline $26 w k$ & $5.69 \pm 0.04$ & $5.77 \pm 0.05$ & $-0.08(-0.21$ to 0.04$)$ \\
\hline $52 \mathrm{wk}$ & $5.64 \pm 0.05$ & $5.78 \pm 0.05$ & $-0.14(-0.29$ to 0$)$ \\
\hline \multicolumn{4}{|c|}{ Fasting blood glucose, $\mathrm{mmol} / \mathrm{L}$} \\
\hline 26 wk & $5.78 \pm 0.13$ & $6.12 \pm 0.13$ & $-0.34(-0.70$ to 0.02$)$ \\
\hline $52 \mathrm{wk}$ & $8.10 \pm 0.88$ & $7.62 \pm 1.23$ & $0.48(-2.50$ to 3.45$)$ \\
\hline \multicolumn{4}{|c|}{ Systolic blood pressure } \\
\hline $26 \mathrm{wk}$ & $120.27 \pm 1.08$ & $125.53 \pm 1.10$ & $-5.26(-8.30$ to -2.22$)$ \\
\hline $52 \mathrm{wk}$ & $117.45 \pm 1.12$ & $124.00 \pm 1.13$ & $-6.55(-9.70$ to -3.42$)$ \\
\hline \multicolumn{4}{|c|}{ Diastolic blood pressure } \\
\hline 26 wk & $80.42 \pm 0.68$ & $82.80 \pm 0.69$ & $-2.38(-4.29$ to -0.47$)$ \\
\hline $52 \mathrm{wk}$ & $78.36 \pm 0.92$ & $81.69 \pm 0.93$ & $-3.33(-5.92$ to -0.75$)$ \\
\hline \multicolumn{4}{|c|}{$\begin{array}{l}\text { Note: } \mathrm{Cl}=\text { confidence interval, } \mathrm{SE}=\text { standard error. } \\
{ }^{*} \text { To account the repeated measure at } 26 \text { weeks, we used repeated-measures analysis of covariance in a mixed model by including the baseline value as a covariat } \\
\text { for the continuous data and a generalized estimating equations approach for the binary data. } \\
\text { tEvaluated by multiple imputation. }\end{array}$} \\
\hline
\end{tabular}


was admitted to hospital for 1 month after diagnosis of chronic obstructive pulmonary disease. None of these events were deemed related to trial participation.

Additional mild adverse effects reported in the naturopathic group included heart palpitations ( $n$ $=1$ ), indigestion following consumption of phosphatidylcholine $(5 \mathrm{~g} / \mathrm{d} ; n=2)$, and fishy-tasting eructation following ingestion of fish oil capsules $(n=3)$. One participant stopped taking fish oil because of gastrointestinal upset.

\section{Drop outs}

Drop outs ( $n=39 ; 15.9 \%)$ were relatively equally distributed between groups (Figure 1). We attempted to contact these people up to 3 times to request a reason for the withdrawal. We obtained information from 17 people (43.6\%): 5 retired, were fired or moved; 5 lost interest; 4 cited time commitment issues; 1 had a lack of mobility; 1 was told to withdraw by their family physician; and 1 cited personal reasons. None of the reasons occurred predominantly in either group.

\section{Interpretation}

We found a significant reduction in the risk of cardiovascular disease following counselling about nutritional and physical activity provided by naturopathic doctors. The baseline-adjusted prevalence of metabolic syndrome was reduced by $16.9 \%$ over the course of 1 year in comparison to enhanced usual care alone. This implies that 1 in 6 individuals receiving additional naturopathic care benefit, in comparison to those who do not, by not developing metabolic syndrome over the course of 1 year. In addition, the baseline-adjusted relative 10-year cardiovascular risk decreased by 3.1 percentage points for the group who received naturopathic care. These findings translate into about 3 fewer people out of 100 with intermediate risk who receive naturopathic care experiencing a serious cardiovascular event (e.g., stroke, heart attack or death) during the next 10 years compared with those who receive usual care.

The results of our study are consistent with those from other pragmatic trials that have studied lifestyle programs for the prevention of metabolic disease. The Diabetes Prevention Program successfully combined diet- and exercise-based interventions to reduce the incidence of diabetes by 58\%. ${ }^{23-25}$ More recently, the large Look AHEAD (Action for Health in Diabetes) trial found that an intensive lifestyle intervention significantly improved major cardiovascular risk factors compared with standard diabetes support and education. ${ }^{26}$ These risk factors included weight, cardiovascular fitness, glycated hemo- globin, systolic and diastolic blood pressure, HDL and triglycerides. The positive changes seen were sustained for 4 years. It is difficult to fully compare the Look AHEAD study with ours, however, because they did not consider compound measures of risk (i.e., Framingham 10-year risk or metabolic syndrome).

\section{Strengths and limitations}

The pragmatic design of our trial, in which both the intervention and control interventions were similar to care in the community, increases its generalizability and applicability to real-world settings.

We did not observe a sufficient number of cardiovascular events to compare the incidence between groups. Although we used validated estimates of composite risk of cardiovascular disease, we do not know whether our estimates are over- or under-estimates of the true differences in absolute risk of events between groups. We lost an appreciable number of patients to follow-up, and we did not model the possible impact of loss to follow-up on the results.

The incidence of metabolic syndrome at baseline was nonsignificantly higher in the intervention group than in the control group. Although we adjusted for baseline values in our analysis, we cannot rule out the possibility of regression to the mean as a source of bias in our results.

We asked whether naturopathic care, in addition to usual primary care, reduces the cardiovascular risk of postal workers. Some may perceive this as an unfair comparison and would prefer that we had asked whether the addition of, for example, 7 sessions of naturopathic care to usual care reduced cardiovascular risk compared to the addition of 7 sessions with a family physician. The design of such a trial would have endeavoured to ensure a similar number of exposures to health care providers in both groups. Those who would prefer us to have asked the latter question might reasonably suggest that our design was unfair and was geared toward showing a benefit in the intervention group.

Our intervention differed from routine clinical practice in both study groups. In the enhanced usual care group, naturopathic doctors measured risk factors 3 times during the course of the study, and participants were encouraged to report the results to their family physicians. Presumably, this additional measurement and communication to physicians within the control group would have enhanced standard care and decreased any differences between the intervention and control groups.

We did not assess for possible contamination between groups and, as such, this could have biased the results. However, this bias, if present, 
would have diluted the comparative beneficial results seen in the naturopathic group. Based on the pragmatic study design and the large number of therapies suggested, the contribution of conventional lifestyle modification compared with the use of natural products to reduce risk in the naturopathic group is unclear.

Also because of the pragmatic design, this trial did not, nor could not effectively, blind trial participants or clinicians to allocation. As a result, the results are susceptible to expectation bias and potentially to measurement bias

\section{Conclusion}

According to the American Heart Association, the "prime emphasis in management of the metabolic syndrome per se is to mitigate the modifiable, underlying risk factors (obesity, physical inactivity, and atherogenic diet) through lifestyle changes. ... Then, if absolute risk is high enough, consideration can be given to incorporating drug therapy to the regimen.." Primary health care that provides in-depth counselling around diet and lifestyle is uniquely poised to help comanage metabolic risk factors. We have shown that naturopathic care is a feasible and potentially effective adjunct to usual medical care in reducing the incidence of metabolic syndrome and cardiovascular risk.

Further investigation of the potential for complementary naturopathic care to support general practice in preventing chronic diseases, including cardiovascular disease, is warranted. Future trials should include larger sample sizes and robust measures to ensure participant adherence to individual elements of treatment, potentially improving attribution of the results to individual therapies.

\section{References}

1. Leading causes of death in Canada, 2007. Ottawa (ON): Statistics Canada; 2010. Available: www.statcan.gc.ca/pub/84-215-x /2010001/hl-fs-eng.htm (accessed 2011 Apr. 15).

2. Yusuf S, Hawken S, Ounpuu S, et al. Effect of potentially modifiable risk factors associated with myocardial infarction in 52 countries (the INTERHEART study): case-control study. Lancet 2004;364:937-52.

3. Gami AS, Witt BJ, Howard DE, et al. Metabolic syndrome and risk of incident cardiovascular events and death: a systematic review and meta-analysis of longitudinal studies. J Am Coll Cardiol 2007;49:403-14

4. Lloyd-Jones D, Adams RJ, Brown TM, et al. Heart disease and stroke statistics-2010 update: a report from the American Heart Association [published erratum in Circulation 2010;121:e260]. Circulation 2010;121:e46-215.

5. Grundy SM, Cleeman JI, Daniels SR, et al. Diagnosis and management of the metabolic syndrome: an American Heart Association/National Heart, Lung, and Blood Institute scientific statement. Circulation 2005;112:2735-52.

6. Balady GJ, Williams MA, Ades PA, et al. Core components of cardiac rehabilitation/secondary prevention programs: 2007 update: a scientific statement from the American Heart Association Exercise, Cardiac Rehabilitation, and Prevention Committee, the Council on Clinical Cardiology; the Councils on Cardiovascular Nursing, Epidemiology and Prevention, and Nutrition, Physical Activity, and Metabolism; and the American Associa- tion of Cardiovascular and Pulmonary Rehabilitation. Circulation 2007; 115:2675-82.

7. Roblin D, Diseker RA III, Orenstein D, et al. Delivery of outpatient cardiac rehabilitation in a managed care organization. $J$ Cardiopulm Rehabil 2004;24:157-64.

8. Suaya JA, Shepard DS, Normand SL, et al. Use of cardiac rehabilitation by Medicare beneficiaries after myocardial infarction or coronary bypass surgery. Circulation 2007;116:1653-62.

9. Bradley R, Kozura E, Kaltunas J, et al. Observed changes in risk during naturopathic treatment of hypertension. Evid Based Complement Alternat Med 2011;2011:826751.

10. Bradley R, Kozura E, Buckle H, et al. Description of clinical risk factor changes during naturopathic care for type 2 diabetes. J Altern Complement Med 2009;15:633-8.

11. Oberg EB, Bradley RD, Allen J, et al. CAM: naturopathic dietary interventions for patients with type 2 diabetes. Complement Ther Clin Pract 2011;17:157-61.

12. Lichtenstein AH, Appel LJ, Brands M, et al. Diet and lifestyle recommendations revision 2006: a scientific statement from the American Heart Association Nutrition Committee. Circulation 2006; 114:82-96.

13. Jenkins DJ, Chiavaroli L, Wong JM, et al. Adding monounsaturated fatty acids to a dietary portfolio of cholesterol-lowering foods in hypercholesterolemia. CMAJ 2010;182:1961-7.

14. de Lorgeril M, Salen P, Martin JL, et al. Mediterranean diet, traditional risk factors, and the rate of cardiovascular complications after myocardial infarction: final report of the Lyon Diet Heart Study. Circulation 1999;99:779-85.

15. Bays HE, McKenney J, Maki KC, et al. Effects of prescription omega-3-acid ethyl esters on non-high-density lipoprotein cholesterol when coadministered with escalating doses of atorvastatin. Mayo Clin Proc 2010;85:122-8.

16. Brown L, Rosner B, Willett WW, et al. Cholesterol-lowering effects of dietary fiber: a meta-analysis. Am J Clin Nutr 1999;69:30-42.

17. Hamilton SJ, Chew GT, Watts GF. Coenzyme Q10 improves endothelial dysfunction in statin-treated type 2 diabetic patients. Diabetes Care 2009;32:810-2.

18. D'Agostino RB Sr, Vasan RS, Pencina MJ, et al. General cardiovascular risk profile for use in primary care: the Framingham Heart Study. Circulation 2008;117:743-53.

19. Ware JJE. The SF-36 Health Survey In: Spilker B, editor. Quality of life and pharmacoeconomics in clinical trials. 2nd ed. Philidelphia (PA): Lippencott-Raven; 1996.

20. Paterson C. Measuring outcomes in primary care: a patient generated measure, MYMOP, compared with the SF-36 health survey. BMJ 1996;312:1016-20.

21. Paterson C, Britten N. In pursuit of patient-centred outcomes: a qualitative evaluation of the "Measure Yourself Medical Outcome Profile." J Health Serv Res Policy 2000;5:27-36.

22. Paterson C, Langan CE, McKaig GA, et al. Assessing patient outcomes in acute exacerbations of chronic bronchitis: the measure your medical outcome profile (MYMOP), medical outcomes study 6-item general health survey (MOS-6A) and EuroQol (EQ-5D). Qual Life Res 2000;9:521-7.

23. Eriksson MK, Franks PW, Eliasson M. A 3-year randomized trial of lifestyle intervention for cardiovascular risk reduction in the primary care setting: the Swedish Bjorknas study. PLOS ONE 2009;4:e5195.

24. Knowler WC, Barrett-Connor E, Fowler SE, et al. Reduction in the incidence of type 2 diabetes with lifestyle intervention or metformin. N Engl J Med 2002;346:393-403.

25. Tuomilehto J, Lindstrom J, Eriksson JG, et al. Prevention of type 2 diabetes mellitus by changes in lifestyle among subjects with impaired glucose tolerance. N Engl J Med 2001;344:1343-50.

26. Wing RR. Long-term effects of a lifestyle intervention on weight and cardiovascular risk factors in individuals with type 2 diabetes mellitus: four-year results of the Look AHEAD trial. Arch Intern Med 2010;170:1566-75.

Competing interests: Kieran Cooley has provided expert advisory commentary on microbiota for gastrointestinal health for Bayer. He holds grants from the Canadian Complementary and Alternative Medicine Research Fund, the Lotte and John Hecht Memorial Foundation, SickKids Foundation, HomeoNet Research Fund, the Interdisciplinary Network of Complementary and Alternative Medicine Research Fund and the First Nations Inuit Health Branch, Health Canada. Heidi Fritz has received payment for manuscript preparation from Integrative Healthcare Practitioners. Serenity Aberdour is scientific advisor for SISU, a distributor of natural health products. Patricia Herman has received consulting fees and payment for writing or reviewing manuscripts from the Canadian College of Naturopathic Medi- 
cine. Philip Rouchotas has served as a consultant for Nutritional Fundamentals of Health and is Editor-in-Chief of Integrated Healthcare Practitioners. Ryan Bradley has served as a consultant for Standard Process and has been employed by the Diabetes Action Research and Education Foundation. No competing interests declared for Dugald Seely, Orest Szczurko, Craig Herrington, David Lescheid, Tara Gignac, Bob Bernhardt, Qi Zhou and Gordon Guyatt.

Affiliations: From the Canadian College of Naturopathic Medicine (Seely, Szczurko, Cooley, Fritz, Aberdour, Herrington, Rouchotas, Lescheid, Gignac, Bernhardt), Toronto, Ont.; the Ottawa Hospital Research Institute (Seely), Ottawa, Ont.; the Ottawa Integrative Cancer Centre (Seely), Ottawa, Ont.; the Leslie Dan Faculty of Pharmacy, University of Toronto (Szczurko, Cooley), Toronto, Ont.; the Department of Psychology, University of Arizona (Herman), Tucson, Ariz.; Bastyr University (Bradley), Kenmore, Wash.; and the Department of Clinical Epidemiology and Biostatistics, McMaster University (Zhou, Guyatt), Hamilton, Ont.
Contributors: Dugald Seely, Gordon Guyatt, Orest Szczurko, Kieran Cooley, Bob Bernhardt, Philip Rouchotas, Ryan Bradley, David Lescheid, Heidi Fritz and Tara Gignac conceived and designed the study. Orest Szczurko, Kieran Cooley, Heidi Fritz, Serenity Aberdour and Craig Herrington acquired and collected the data. Qi Zhou, Patricia Herman, Gordon Guyatt and Dugald Seely analyzed the data. All of the authors drafted and/or revised the manuscript for important intellectual information. All authors approved the final version of the manuscript submitted for publication.

Funding: This project was funded by the Joint Benefits Committee of the Canadian Union of Postal Workers and the Canada Post Corporation.

Acknowledgements: The authors thank Seroyal International for providing discounted natural health products to trial participants.

Kieran Cooley was supported by a SickKids Foundation Training Award in Complementary/Alternative Health Care. 